\title{
Comparison of Abdominal Strength and Explosive Strength of Table Tennis Players and Badminton Players in School Students
}

\author{
Chandan Ghosh* \& Supriyo Mondal** \\ *Ph.D. Scholar, Dept. of Physical Education, Visva Bharati University, Santiniketan, W.B., India \\ **Sports Officer, Birla Global Institute, Bhubaneswar, Odisha, India
}

\begin{abstract}
The study was under taken with the purpose of comparing selected physical fitness variables in Table Tennis Players and Badminton Players. The variables selected were Explosive Strength and Abdominal Strength. Sixty male school students were selected as subjects aging 14 year to 16 year (15.17 \pm 0.51$)$ who were actively involved in their respective games. Among these 30 belonged to Badminton game and rest 30 belonged to Table Tennis game. Descriptive Statistics and Independent ' $t$ ' test were employed using IBM SPSS-17 Software. Findings suggest that the players belonging to Badminton game were superior in both Explosive Strength and Abdominal Strength in comparison to the players belonging to Table Tennis game.
\end{abstract}

Keywords: Explosive Strength, Abdominal Strength, School Students, Badminton Players, Table Tennis Players

\section{Introduction}

The study of growth and development of childhood and adolescence are one of the important areas in education as well as physical education. So, physical education teachers and professionals must be acquainted with the nature of development of different motor skills in childhood and adolescent due to participating in different type of activities (Mondal et al., 2014).

Human body is a gift by nature. Life in the present time is not less than the blessing of God. Scientific discoveries have changed the entire face of our world. It has changed the thorny life into the bed of roses. Good health provides sound and solid foundation on which fitness rests and at the same time fitness provides one of the most important key to health, and living one's life to fullest. The negative effects of degraded physical fitness on both the individual and society are serious and multi-dimensional. It can cause many risk factors to heath including coronary heart disease, certain forms of cancer, hypertension, respiratory problems, and each associated with increases in all cause mortality (Cataldo, 1999). Low levels of physical activity and cardiorespiratory fitness are both associated with higher risk of all cause and disease specific mortality (Thune et al., 1998).

Schools have the potential to improve the health of young people by providing instruction in physical education that promotes enjoyable lifelong physical activity. Diseases and health problem resulting from an inactive lifestyle have their origins early in life. This is when an active life style should be established. Fitness begins at birth and should continue throughout a person's life. Fitness improves general health and it is essential for full and vigorous living. The physically fit child feels more alert and eager to do things. A weak child is a weak brick in the wall of the country. The wealth of a country depends entirely upon the health of every citizen of the country (Sarma, 2015).

The complex nature of physical fitness can be best under stood in terms of its components such as cardiovascular endurance, strength, flexibility, speed, agility and muscular endurance. In addition to these components of physical fitness there are many other factor which contribute to physical fitness including heredity, living standard, nutrition, hygienic conditions, environmental and climate factors etc. (Sallis. et.al., 1992).

The purpose of this study was to compare the school going active male students involved in Table Tennis game and school going active male students involved in Badminton game, so as to find out which of these two categories is more physically fit in response to tests administered. This may help the coaches and parents to promote their children in the respective games according to the innate strength characteristics and requirement.

\section{Methodology}

Subjects: For this study total of 60 male school students were selected as subjects aging 14 year to 16 year $(15.17 \pm 0.51)$ who were actively involved in their respective games. Among these 30 belonged to Badminton game and rest 30 belonged to Table Tennis game from Guwahati, Assam.

Variables selected and criterion measures:

- Flexed Knee Standing Broad Jump for Explosive Strength (distance in meter). 
- $\quad$ Bent Knee Sit Ups for Abdominal Strength (numbers in on minute).

Statistical Technique: The data set was checked for its normality in respect to outliers, skewness, kurtosis, equality of variances etc. Descriptive statistics and Independent ' $t$ ' test was employed to each variables for comparing them. The level of significance chosen was 0.05.IBM SPSS 17 was used to execute the statistical functions.

\section{Results}

The data set was checked for its normality in respect to outliers, skewness, kurtosis, equality of variances etc. It was found to be perfect in all sense to be treated with parametric statistics. After converting the raw data into group data, statistical test were employed to find out necessary information. The results and findings of the descriptive and independent ' $t$ ' test are presented in the tables and illustrations below.

Table 1: Descriptive Test Scores of Explosive Strength and Abdominal Strength of Badminton Players and Table Tennis Players in School Going Students

\begin{tabular}{|l|l|l|l|l|l|}
\hline & Groups & No. of subjects & Mean & Std. Deviation & Std. Error Mean \\
\hline \multirow{2}{*}{ Explosive Strength } & Badminton & 30 & 2.25 & 0.14 & 0.02 \\
\cline { 2 - 7 } & Table Tennis & 30 & 2.12 & 0.13 & 0.02 \\
\hline \multirow{2}{*}{ Abdominal Strength } & Badminton & 30 & 41.23 & 3.83 & 0.70 \\
\cline { 2 - 7 } & Table Tennis & 30 & 35.53 & 4.23 & 0.77 \\
\hline
\end{tabular}

Table: 1 shows the nature and characteristics of fitness scores of Abdominal Strength and Explosive Strength of badminton players and table tennis players in school going students (i.e. number of subjects in each group, mean, standard deviation and standard error of mean).

Table 2: Comparative Analysis of Explosive Strength and Abdominal Strength of Badminton Players and Table Tennis Players in School Going Students

\begin{tabular}{|l|l|l|l|l|l|l|}
\hline & \multicolumn{2}{|l|}{$\begin{array}{l}\text { Levene's Test for Equality } \\
\text { of Variances }\end{array}$} & \multicolumn{2}{l|}{ t-test for Equality of Means } \\
\hline Test Items & F-Value & P-Value & t-value & P-Value & $\begin{array}{l}\text { Percentage } \\
\text { Difference }\end{array}$ & $\begin{array}{c}\text { Mean } \\
\text { Std. } \\
\text { Difference }\end{array}$ \\
\hline Explosive Strength & 0.78 & .382 & $3.76^{*}$ & 0.001 & 5.88 & 0.03 \\
\hline Abdominal Strength & 0.31 & .583 & $5.47^{*}$ & 0.001 & 14.85 & 1.04 \\
\hline
\end{tabular}

*Significant, ' $t$ ' .05 (58) $=2.000$

Levene's Test for equality of variances results shows that the variance of two groups were equal in both the fitness variables as p-Value of both the variables were more than .05 thus two sample t-ratio's assumption is fulfilled.

The scrutiny of table 2 reveals that there lies a statistically significant difference between Explosive Strength of badminton players and table tennis players in school going students ( $\mathrm{t}$-value $=3.76, \mathrm{p}=0.001$. Further statistically significant difference also lies between Abdominal Strength of badminton players and table tennis players in school going students $(\mathrm{t}$-value $=5.47, \mathrm{p}=0.001)$.

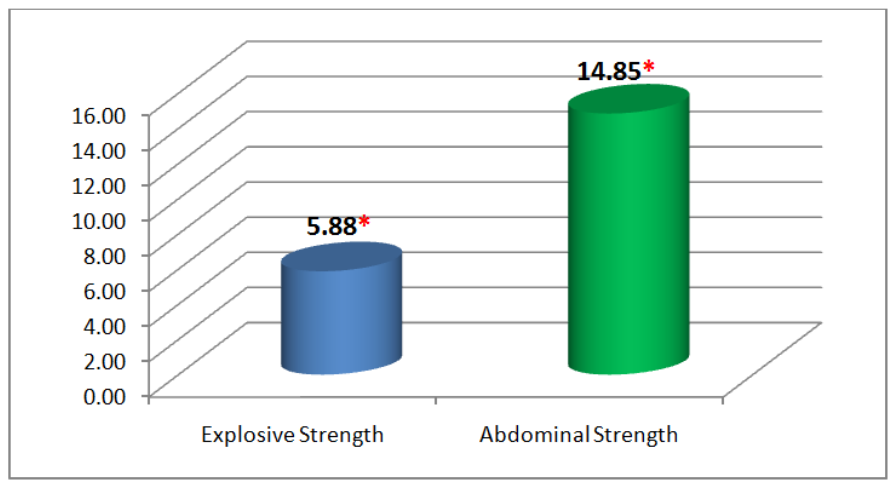

*Significant at 0.05 level

Figure 1: Percentage Difference of Explosive Strength and Abdominal Strength of Badminton Players and Table Tennis Players in School Going Students

The above figure is the graphical representation of the percentage difference of various fitness variables in two different groups. 


\section{Discussion}

The findings that the students involved in Badminton game were found to be in the higher side in explosive strength compared to the students involved in Table Tennis game may be due to the fact that the game of Badminton is played in a relatively larger area than the game of Table Tennis and thus requires and develops more explosive strength for quick movements as well as to return to the initial position while covering the court during game. Again similar results in case of abdominal strength was found, this may be due to the fact that while attacking the shuttlers vigorously contracts their back as well as abdomen very often, whereas the movements involved during table tennis shots are more precise and controlled rather than vigor. In a previous study by Mondal S. \& Kumar P. (2015) while comparing Agility and Flexibility of same group similar trend was found.

\section{Conclusion}

The conclusion which can be drawn on the basis of the present study is the players belonging to Badminton game were in higher side of Explosive Strength and Abdominal Strength than the players belonging to Table Tennis game.

\section{References}

[1]. Bompa, Tudor., and Haff, G. Gregory. (2009). Periodization: Theory and Methodology of Training. 5th ed., Human Kinetics

[2]. Cataldo, C. (1999). Nutrition and Diet Therapy: Principles and Practice. St. Paul: West Publishing company, pp.232-238

[3]. Johnson, B.L., and Nelson, J. K. (2007).Practical measurement for evaluation in physical education. $3^{\text {rd }}$ edition, Surjeet Publication, Delhi. pp 197 and 227-228.

[4]. Kansal, D. K. (2008). Textbook of Applied Measurement, Evaluation \& Sports Selection. $2^{\text {nd }}$ Edition, New Delhi: SSS Publications

[5]. Mondal, S., Dey, T. S., and Varghese, J. (2014). Active Tribal School Going Female Students of Hilly Area Dominates Their Counterpart Residing In Plain Area on Physical Fitness. Wellness Through Physical Activity: Future Perspective, Twentyfirst Century Publications, Patiala, Page No: 330-333

[6]. Mondal, S., and Kumar, P. (2015). Comparison of Flexibility and agility of Table Tennis Players and Badminton Players in School Students. National Journal of Physical Education and Sports Science, 2(1): 81-83

[7]. Sallis, J. F., Hovell, M. F., and Hofstetter, C. R. (1992). Predictors of adoption and maintenance of vigorous physical activity in men and women. Preventive Medicine, 21, 237-251.

[8]. Sarma, B. J. (2015). Comparison of Speed and Endurance of Table Tennis Players and Badminton Players in School Students. Online International Interdisciplinary Research Journal, 5(3): 289-292

[9]. Singh, H. (1995). Science of Sports Training. D. V. S Publication, New Delhi

[10]. Thune, I., Njolstad, I., Lochen, M. L., and Forde O. H. (1998). Physical activity improves the metabolic risk profiles in men and women. Arch Intern Med., 158: 1633-1645.

[11]. Verma, J. P. (2011). Statistical Methods for Sports and Physical Education.Tata McGraw Hill Education Private Ltd 